Published in final edited form as:

Int J Pediatr Obes. 2011 June ; 6(2-2): e144-e153. doi:10.3109/17477166.2010.500387.

\title{
Socioeconomic disparities in trajectories of adiposity across childhood
}

\author{
LAURA D. HOWE ${ }^{1,2}$, KATE TILLING $^{1}$, BRUNA GALOBARDES ${ }^{1}$, GEORGE DAVEY SMITH ${ }^{1,2}$, \\ ANDY R. NESS ${ }^{3}$, and DEBBIE A. LAWLOR ${ }^{1,2}$ \\ ${ }^{1}$ Department of Social Medicine, University of Bristol, UK \\ ${ }^{2} \mathrm{MRC}$ Centre for Causal Analyses in Translational Epidemiology, University of Bristol, UK \\ ${ }^{3}$ Department of Oral and Dental Science, University of Bristol, UK
}

\begin{abstract}
Background-Socioeconomic inequalities in obesity are consistently observed in high-income countries. The development of such inequalities across childhood; however, has not been studied using longitudinal data.
\end{abstract}

Methods-Using data from the Avon Longitudinal Study of Parents and Children (participants were born 1991/2 in South-West England), we modelled trajectories of ponderal index (PI) (N=12 246) from birth to 2 years and body mass index (BMI) $(\mathrm{N}=11$ 380) from 2 to 10 years. Individual trajectories were estimated using mixed-effects models, and differences in trajectories by socioeconomic position (measured by maternal education) were investigated.

Results-There was little socioeconomic patterning of PI from birth to 2 years. Socioeconomic differences in BMI began to emerge by 4 years old, and widened with increasing age. Amongst girls there was a clear gradient across all categories of maternal education by age 8 , with daughters of more educated women being less adipose. Amongst boys, sons of degree-educated women had lower BMI but there was little difference between the lower maternal education categories. By 10 years old the mean BMI difference between the highest and lowest maternal education category was $0.38 \mathrm{~kg} / \mathrm{m}^{2}$ for boys and $0.89 \mathrm{~kg} / \mathrm{m}^{2}$ for girls. The results imply that interventions to prevent inequalities in childhood obesity should begin in pre-school years.

\section{MeSH Keywords}

Child; longitudinal studies; obesity; socioeconomic factors

\section{Keywords}

ALSPAC Correspondence: Laura D. Howe, Department of Social Medicine, Oakfield House, Oakfield Grove, Bristol BS8 2BN, UK.
laura.howe@ bristol.ac.uk.

Declaration of interest: All funding sources are declared in the acknowledgements section. The authors report no conflicts of interest. The authors alone are responsible for the content and writing of the paper. 


\section{Introduction}

The prevalence of obesity in children and adolescents in the United Kingdom has almost tripled in the past 20 years (1), and the picture is similar in many developed nations (2-5). Adiposity in childhood tends to persist ('track') into later life. A systematic review identified 13 high-quality studies, all of which demonstrated tracking of childhood ( $₫ 2$ years) and adolescent ( $\geq 13$ to $\leq 18$ years) overweight into adulthood (6). Furthermore, rapid weight gain in infancy is associated with later obesity $(7,8)$.

Socioeconomic disparities in adiposity are consistently observed in high-income countries, with both adults (9) and children (10) in lower socioeconomic groups tending to be more adipose. The age at which socioeconomic differences emerge is; however, unclear. A systematic review of cross-sectional studies, and a cross-national cross-sectional study not included in the review, suggest that socioeconomic differentials are present from at least age 5 , with some evidence they may decrease around puberty, emerging again in adulthood $(10,11)$. The few studies that have used longitudinal data have explored trajectories from late childhood only. For example, one study explored differentials in trajectories from age 11 (12) and a second from age 9 (13). To our knowledge no previous study has reported the emergence of socioeconomic differentials in adiposity in a cohort with repeat measurements since birth. Given the important influence of adiposity to many adverse health outcomes, an understanding of when inequalities in adiposity emerge is likely to be important in informing the development of interventions to reduce inequalities in these health outcomes.

To describe the emergence of inequalities in obesity in contemporary children in a highincome country, we examined socioeconomic differentials in trajectories of adiposity from birth to age 10 years in the Avon Longitudinal Study of Parents and Children (ALSPAC). There is some evidence that shifting trends in adiposity are due to an upwards shift in the top end of the adiposity distribution (3). Therefore we also explored whether the distribution of adiposity is more right-skewed in lower socioeconomic groups to assess whether this could be driving socioeconomic differences in adiposity.

\section{Materials and methods}

\section{Study population and ethics}

ALSPAC is a prospective birth cohort study in South-West England (14), full details of which are available on the study website (www.bristol.ac.uk/alspac). Pregnant women resident in one of three Bristol based health districts with an expected delivery date between 1 April 1991 and 31 December 1992 were invited to participate. Of these women, 14541 were recruited. From these pregnancies, there were 14062 live-born children, 13988 of whom were alive at one year. Follow-up has included parent- and child-completed questionnaires, links to routine data, and clinic attendance. A random sub-sample of children from the last 6 months of recruitment ("Children in Focus" group, approximately 10\% of the cohort) were invited to clinics between ages 4 months and 5 years; all children were invited to yearly clinics from age 7 to 10 years. Ethical approval was obtained from the ALSPAC Law and Ethics Committee and the Local Research Ethics Committees. 


\section{Measurements}

A questionnaire at 32 weeks gestation asked mothers to report their educational attainment, which was categorised as below O-Level (Ordinary Level; exams taken in different subjects usually at age 15-16 at the completion of legally-required school attendance, equivalent to today's UK General Certificate of Secondary Education), O-Levelonly,A-Level(AdvancedLevel; exams taken in different subjects usually at age 18), or university degree or above. We also examined socioeconomic differentials with household occupational social class, but as results were the same as those presented here for education, these are not presented or discussed further (available from authors on request).

Birth weight was extracted from medical records, and birth length was measured by ALSPAC staff that visited newborns soon after birth (median 1 day, range 1-14 days), using a Harpenden Neonatometer. Height and weight data are available from several sources: extracted from health visitor records (routine measurements taken as part of standard child care in the UK, in this sample we had up to four measurements taken on average at 2,10,21, and 48 months of age), parental reports from questionnaires, and measurements from clinic attendances. At clinics, height was measured to the last complete mm using the Harpenden Stadiometer. At clinics before age 7, weight was measured using Fereday $100 \mathrm{~kg}$ combined scale (4-month clinic), Soenhle scale or Seca scale model 724 (8-month clinic), Seca 724 or Seca 835 (12-month clinic), Seca 835 (18-months onwards). At clinics after 7 years, weight was measured using the Tanita Body Fat Analyser (Model TBF 305). Children were dressed in light clothes without shoes for weight measurements.

Patterns of BMI change in early childhood are extremely complicated; BMI increases in the first few months of life, decreases until approximately age 3-7 years, and subsequently increases again. Given this, and to be consistent with the International Obesity Task Force who only presented BMI cut-offs for overweight and obesity for children over 2 years of age (15), we decided not to model BMI from birth. Rather, ponderal index (PI) was used as the measure of adiposity from birth to 2 years. BMI was modelled from 2 to 10 years. We preferred to use BMI rather than PI after 2 years, as BMI is more commonly used both in the research literature and in clinical practice. PI was calculated as weight $(\mathrm{kg})$ divided by height $(\mathrm{m})$ cubed; BMI was calculated as weight $(\mathrm{kg})$ divided by height $(\mathrm{m})$ squared.

\section{Statistical analysis}

Implausible measurements ( $>4$ standard deviation [SD] from the mean) were dropped (approximately $0.1 \%$ of measurements). All other available measures were used in analyses. We demonstrated in previous work that routine measurements of height and weight (taken by health visitors) have good accuracy (16), but measurements reported by children's carers in questionnaires are likely to be less accurate (17). To account for this, a binary indicator of measurement source (research clinic or health records versus questionnaire) was included in all models.

We estimated individual adiposity trajectories using linear spline mixed-effects models, using the statistical package MLwiN version 2.10 (www.cmm. bristol.ac.uk/MLwiN/ index.shtml). Such models allow for the change in scale and variance of adiposity over time 
and use all available data from eligible children under a missing at random assumption. They allow for individual variation in growth trajectories, as random effects allow each individual to have different intercepts and slopes. Models for PI (birth to 2 years) and BMI (2 to 10 years) were constructed separately for boys and girls. Knot points were set at 2 months for boys' PI; 1 and 4 months for girls' PI; 56, 67, 73, 79, and 105 months for boys' BMI; 60, 65, 75, 81, and 103 months for girls' BMI. Full details of the statistical modelling are provided in the Web Supplementary material.

Actual and predicted measurements (from the multilevel models) were compared to assess model fit.To verify that models were not dominated by individuals with large numbers of measurements, models were re-run with random subsamples of observations within each individual, such that no individual had more than six (the $75^{\text {th }}$ centile) measurements. The coefficients from this model were very similar to those from the full model, as were residual estimates $(\mathrm{R} \searrow 0.9)$.

To assess whether the distribution of BMI was more right-skewed in lower socio-economic position (SEP) groups, histograms of BMI and the extent of skewness were examined for maternal education categories. Skewness is a measure of the asymmetry of the probability distribution of a random variable. Technically it is the $3^{\text {rd }}$ standardized moment.

\section{Results}

\section{Data and population}

PI measures were available on 6323 boys and 5923 girls who also had data on maternal education, median four measurements, inter-quartile range (IQR) 3 to 6 . BMI measures were available on 5850 boys and 5530 girls who also had data on maternal education, median four measurements, IQR 3 to 6 (Table I). There was little evidence of differences between individuals included in our models and the full ALSPAC cohort in terms of maternal education, birth length and weight, or maternal pre-pregnancy BMI (Supplementary Table I). Approximately $30 \%$ of children had mothers in the lowest education category, approximately $13 \%$ were in the highest category (Table I). The number of measurements was greater in higher socioeconomic groups, e.g., the median was three BMI measures in the lowest maternal education category and five in the highest category. The socioeconomic differential in the number of measurements was smaller for PI (e.g., median four PI measures in the lowest maternal education category and five in the highest category) as most children have routine measures from health visitor records.

Supplementary Figures 2 and 3 show the average predicted PI and BMI trajectories across childhood from our models.

\section{Model fit}

Autocorrelation is residual correlation between an individual's measurements as a decreasing function of the difference in the age at measurement, a phenomenon that can cause problems in growth models, particularly when repeated measurements are close together in time as they are in these analyses (18). We examined the correlation of the difference between a measurement and the measurement predicted by the model and this 
difference for the previous measurement to give an indication of the extent of autocorrelation in our models. This was -0.21 for boys and -0.24 for girls for ponderal index. For BMI, it was 0.27 for boys and 0.22 for girls. These values indicate weak levels of autocorrelation and given the goodness of fit of our model as demon-strated in Table II, together with computational difficulties in incorporating autocorrelation into growth models in MLwiN, we did not account for autocorrelation in further analyses. Despite the skewed distribution of BMI, the residuals for each period of PI and BMI change were approximately normally distributed (residual diagnostic plots available from authors on request).

\section{Socioeconomic differentials in ponderal index}

There is no clear socioeconomic patterning of PI at birth in either boys or girls (Table III). Figures 1 and 2 show the trajectories of PI from birth to 2 years for each maternal education category (for boys and girls, respectively). For both boys and girls, a likeli-hood ratio test indicated strong evidence of an over-all interaction between maternal education and PI trajectories (two-sided $P<0.001$ ). However, when the predicted values of PI at fixed ages were assessed, differences between maternal education categories were small (Table III). Amongst boys, there is no clear pattern of socioeconomic differential in PI between birth and 2 years. Amongst girls, there is some indication that girls of degree-educated women tend to have lower PI, but the differences are very small, and there is no clear gradient across the other three maternal education categories.

\section{Socioeconomic differentials in body mass index}

For both boys and girls, a likelihood ratio test indicated strong evidence of an overall interaction between maternal education and BMI trajectories (two-sided $P<0.001$ ).

Amongst boys, all maternal education categories have similar BMI levels from 2 to 4 years (Table IV, Figure 3). Between 2 and 6 years, the BMI of boys with degree-educated mothers is decreasing at a faster rate than the other maternal education categories. By 7 years, the socioeconomic patterning of BMI in boys has stabilised, with sons of degree-educated women having lower BMI and a lower rate of BMI increase than the other three maternal education categories. Mean BMI in sons of the three lower maternal education categories remain similar in the trajectories. The magnitude of the BMI difference between sons of the degree-educated mothers and the other categories increases over time between 7 to 10 years. By 10 years old, boys in the degree category of maternal education have on average a BMI $0.38 \mathrm{~kg} / \mathrm{m}^{2}$ lower than boys in the less then O-Level maternal education category (note that the standard deviation of boys' BMI measures between 105-120 months of age is 2.54 , so this difference represents approximately $15 \%$ of a standard deviation).

Amongst girls, daughters of degree-educated women have slightly higher BMI at 2 years than the lower maternal education categories (mean BMI in degree group $16.55 \mathrm{~kg} / \mathrm{m}^{2}$ compared with $16.40 \mathrm{~kg} / \mathrm{m}^{2}$ in less than O-Level group) and their BMI decreases at a faster rate than the other maternal education categories between 2 and 6 years. By 4 years old, daughters of degree-educated women have lower BMIs than lower maternal education categories. From 7 years onwards, the socioeconomic differential in BMI across all categories of maternal education increases (Table IV, Figure 4). By 8years old, there is a 
clear socioeconomic gradient of BMI across all four categories of maternal education, with BMI decreasing with increasing maternal education. By 10 years old, girls in the degree category of maternal education have on average a BMI $0.89 \mathrm{~kg} / \mathrm{m}^{2}$ lower than girls in the less then O-Level maternal education category (note that the standard deviation of girls' BMI measures between 105-120 months of age is 2.68 , so this difference represents approximately $33 \%$ of a standard deviation).

\section{Socioeconomic differentials in BMI distribution}

Examining the skewness of the BMI distribution across categories of maternal education revealed no clear socioeconomic differences in skewness of BMI amongst girls. In boys there was some indication that sons of mothers with a university degree had a less rightskewed distribution than the other three categories of maternal education, skewness of BMI in sons of degree-educated women was 1.1 compared with 1.3 in all other maternal education categories (Figures 5 and 6 for boys and girls, respectively, and Supplementary Table II).

\section{Discussion}

\section{Main findings}

Whilst many studies have shown that socioeconomic inequalities in adiposity are now common in children across high-income countries (10), including cross-sectional analyses of this population at ages 10 years (19) and 11 years (20), few studies have been able to investigate the patterns of socioeconomic differentials in adiposity across childhood using longitudinal data, particularly in early childhood. In this study, we have examined socioeconomic differences in trajectories of adiposity from birth to 10 years old. We found very little evidence of socioeconomic patterning of adiposity in infants and very young children. Socioeconomic differentials in adiposity began to emerge at about age 4 years, becoming stronger with age, and demonstrating clear and consistent patterns from about age 7 years. In boys, the differential was due primarily to the difference between the degree category and all other maternal education categories. In girls, the pattern was similar to boys until age 8 at which time an adiposity gradient across all four categories of maternal education emerged. The socioeconomic inequality was wider in girls than boys.

There is some evidence (from mean-difference plots of the BMI in successive crosssectional surveys) that increasing mean BMIs are due to an upwards shift in the top end of the distribution, i.e., those at the top end of the BMI distribution are getting more adipose (3). We therefore hypothesised that socioeconomic differences in adiposity may be due to increased BMI amongst those at the top end of the distribution. In this study, we did not find any evidence of increased skewness of the BMI distribution of children with decreasing maternal education in girls, and in boys there was only slightly less skew in the distribution of the degree category compared with all other maternal education categories. However, we are modelling here BMI, an index of weight for height, and different trends in fat and lean mass could explain any skewness. 


\section{Changes in socioeconomic inequalities in adiposity over time}

The relationship between SEP and BMI appears to be changing over time. In earlier cohort studies, socioeconomic differentials in childhood adiposity were not observed. A review of older cohorts published in 2002 (children aged up to 18 years and young adults aged up to 24 years, who had largely been born between the 1940s and 1980s) did not demonstrate socioeconomic inequalities in adiposity in childhood, but did find evidence of socioeconomic patterning of adiposity in young adults (21). A study of Glasgow students (attending the university health service between 1948 and 1968) did not find social patterning of early adult adiposity (mean age 23 years in men and 20 years in women), but in these same individuals childhood SEP predicted later adult BMI (mean age 39 years in men and 36 years in women), despite little heterogeneity in their adult SEP (22). A study in France compared two cross-sectional studies of 5-year-olds, one in 1989 and another in 1999. Between the two time points, prevalence of overweight and obesity remained constant in those with higher parental occupational class. In the intermediate classes, there was an increase only in the BMI of those children at the top of the BMI distribution, i.e., the heaviest children became heavier still. In the lower social class; however, there was an increase in BMI across the whole population (4). In participants of the 1958 birth cohort study, there was little or no socioeconomic inequality in childhood adiposity; by contrast amongst the participants' offspring (born between 1982 and 1987) higher SEP was associated with lower adiposity (23).

The fact that we observe the emergence of socioeconomic inequalities in adiposity in children as young as 4 years old, and the fact that these inequalities are widening with increasing age of the children suggests that these children may well demonstrate even wider socioeconomic inequalities in adulthood obesity, cardiovascular diseases, and diabetes than those experienced by contemporary adults. Public health interventions addressing obesity should therefore include young, pre-school children. Population-based interventions, if successful, may have a greater overall population impact on the reduction of obesity and its associated complications than interventions targeted at lower socioeconomic groups. However, it is well known that many interventions are initially taken up to a greater extent by more socially advantaged groups, leading to a widening of socioeconomic differentials. In order to reduce socioeconomic inequalities in obesity, cardiovascular disease and diabetes, it will be necessary to either target interventions at disadvantaged groups, or to attempt to promote their greater participation in population-wide interventions. Our study used maternal education as the measure of SEP, although findings were very similar when using paternal education or household occupational social class (results available from authors on request). Socioeconomic factors are likely to be associated with child adiposity through a number of pathways, including knowledge, attitudes, financial and other constraints on nutrition and physical activity patterns. Further research investigating the behavioural and other factors that explain socioeconomic inequalities in adiposity will be useful to inform intervention design.

\section{Gender differences in socioeconomic inequalities in adiposity}

We observed wider inequalities in adiposity in girls compared with boys. This is consistent with findings in adults (9), but a systematic review of studies of children from developed 
countries published since 1989 showed no gender difference in inequalities in adiposity in over half of the 19 studies reporting associations separately for boys and girls, and mixed findings in the remaining studies (10).

The reasons for inequalities in adiposity being wider in girls are unclear. There is some evidence that boys are more likely than girls to participate in sport, regardless of their SEP (24), and that the inverse association between physical activity and adiposity tends to be stronger among boys than girls $(25,26)$. However, there is little evidence of a socioeconomic gradient in objectively measured physical activity within ALSPAC (27), although there is evidence that boys are more likely to participate in moderate-to-vigorous activity (27), which has been shown to be more strongly associated with reduced fat mass than total activity (26). In the context of adults, McLaren discusses the possibility that men place value on larger body size, associating it with power and dominance, whereas women value thinness, and proposes this as at least a partial explanation for the wider inequalities in adiposity in women compared with men (9). The relevance of this to young children is questionable, although there is some evidence from a study of 10-14-year-olds that girls wish to be thinner whereas boys wish to be larger (28).

\section{Strengths and limitations}

The main strengths of this study are its uniqueness in examining adiposity trajectories from birth to age 10 in a large sample size with a large number of repeat measurements and in exploring differentials in the shape of the BMI distribution across different socioeconomic groups.

Our modelling approach has allowed us to examine trajectories of adiposity across childhood, taking account of the different timings and numbers of measurements between children. By using a linear spline model, we have been able to simplify the trajectories, whilst retaining good fit between actual and predicted values. Drop out from any research study is likely to be socially patterned. Whilst in our data we have fewer measurements for lower SEP children, there are very few children in the ALSPAC cohort who did not have at least one measurement included in these analyses. Furthermore, there are no differences in the SEP distribution between those children included in these models and the full ALSPAC cohort. Missing data is therefore unlikely to have caused bias in these analyses.

BMI has been shown to underestimate socioeconomic inequalities in adiposity in childhood compared with dual x-ray (DXA) assessed fat mass (19). Our findings may, therefore, underestimate the degree of socioeconomic inequality, but without repeat measurements of DXA-assessed fat mass across age from birth to 10 years, we are unable to assess this. To our knowledge no other study has repeat measurements of DXA across infancy and early childhood in a large cohort.

\section{Supplementary material available online}

Refer to Web version on PubMed Central for supplementary material. 


\section{Acknowledgements}

We are extremely grateful to all the families who took part in this study, the midwives for their help in recruiting them, and the whole ALSPAC team, which includes interviewers, computer and laboratory technicians, clerical workers, research scientists, volunteers, managers, receptionists, and nurses.

We thank Paul Clarke (Centre for Market and Public Organisation, University of Bristol), Fiona Steele (Centre for Multilevel Modelling, University of Bristol), for statistical advice and comments on an earlier draft.

Funding

This work was supported by a grant from the UK Economic and Social Research Council (RES-060-23-0011). This grant provides the salary for LH. BG is funded by a UK Medical Research Council Fellowship in Health of the Public. The UK Medical Research Council; the Wellcome Trust and the University of Bristol provide core funding support for ALSPAC. The UK Medical Research Council and the University of Bristol provide core funding for the MRC Centre of Causal Analyses in Translational Epidemiology. The views expressed in this paper are those of the authors and not necessarily those of any funding body or others whose support is acknowledged. The funders had no role in study design, data collection and analysis, decision to publish, or preparation of the manuscript.

\section{References}

1. Lobstein TJ, James WPT, Cole TJ. Increasing levels of excess weight among children in England. Int J Obes Relat Metab Disord. 2003; 27:1136-8. [PubMed: 12917722]

2. Ogden CL, Flegal KM, Carroll MD, Johnson CL. Prevalence and trends in overweight among US children and adolescents, 1999-2000. JAMA. 2002; 288(14):1728-32. [PubMed: 12365956]

3. Flegal KM, Troiano RP. Changes in the distribution of body mass index of adults and children in the US population. Int J Obes Relat Metab Disord. 2000; 24:807-18. [PubMed: 10918526]

4. Romon M, Duhamel A, Weill J. Influence of social class on time trends in BMI distribution in 5year-old French children from 1989 to 1999. Int J Obes Relat Metab Disord. 2005; 29:54-9.

5. Hulens M, Beunen G, Lefevre J, Thomis M, Philippaerts R, Borms J, Vrijens J, Lysens R, Vansant G. Trends in BMI among Belgian children, adolescents and adults from 1969 to 1996. Int J Obes Relat Metab Disord. 2001; 25:395-9. [PubMed: 11319638]

6. Singh AS, Mulder C, Twisk JW, Van Mechelen W, Chinapaw MJM. Tracking of childhood overweifht into adulthood: a systematic review of the literature. Obes Rev. 2008; 9:474-88. [PubMed: 18331423]

7. Ong KK, Ahmed ML, Emmett PM, Preece MA, Dunger DB. Association between postnatal catchup growth and obesity in childhood: prospective cohort study. BMJ. 2000 Apr 8; 320(7240):967-71. [PubMed: 10753147]

8. Ong KK, Loos RJF. Rapid infancy weight gain and subsequent obesity: Systematic reviews and hopeful suggestions. Acta Paediatr. 2006; 95:904-8. [PubMed: 16882560]

9. McClaren L. Socioeconomic Status and Obesity. Epidemiol Rev. 2007; 29:29-48. [PubMed: 17478442]

10. Shrewsbury V, Wardle J. Socioeconomic Status and Adiposity in Childhood: A Systematic Review of Cross-sectional Studies 1990-2005. Obesity. 2008; 16:275-84. [PubMed: 18239633]

11. Wang Y. Cross-national comparison of childhood obesity: the epidemic and the relationship between obesity and socioeconomic status. Int J Epidemiol. 2001; 30:1129-36. [PubMed: 11689534]

12. Wardle J, Henning Brodersen N, Cole TJ, Jarvis MJ, Boniface DR. Development of adiposity in adolscence: five year longitudinal study of an ethnically and socioeconomically diverse sample of young people in Britain. BMJ. 2006; 332:1130-5. [PubMed: 16679329]

13. Wright CM, Parker L, Lamont D, Craft AW. Implications of childhood obesity for adult health: findings from thousand families cohort study. BMJ. 2001 Dec 1; 323(7324):1280-4. [PubMed: 11731390]

14. Golding J, Pembrey M, Jones R, ALSPAC Study Team. ALSPAC - The Avon Longitudinal Study of Parebts and Cheildren I. Study Methodology. Paediatr Perinat Epidemiol. 2001; 15:74-87. [PubMed: 11237119] 
15. Cole TJ, Bellizzi MC, Flegal KM, Dietz WH. Establishing a standard definition for child overweight and obesity worldwide: international survey. BMJ. 2000; 320:1240-3. [PubMed: 10797032]

16. Howe LD, Tilling K, Lawlor DA. Accuracy of height and weight data from child health records. Arch Dis Child. 2009; 94:950-4. [PubMed: 19689966]

17. Dubois L, Girad M. Accuracy of maternal reports of pre-schoolers' weights and heights as estimates of BMI values. Int J Epidemiol. 2007 Feb 1; 36(1):132-8. [PubMed: 17510077]

18. Goldstein H, Healy MJR, Rasbash J. Multilevel Time-Series Models with Applications to Repeated-Measures Data. Stat Med. 1994; 13:1643-55. [PubMed: 7973240]

19. Ness AR, Leary S, Reilly J, Wells J, Tobias J, Clark E, Davey Smith G, The ALSPAC Study Team. The social patterning of fat and lean mass in a contemporary cohort of children. Int J Pediatr Obes. 2006; 1:59-61. [PubMed: 17902216]

20. Matijasevich A, Victora C, Golding J, Barros F, Menezes A, Araujo C, Smith G. Socioeconomic position and overweight among adolescents: data from birth cohort studies in Brazil and the UK. BMC Public Health. 2009; 9(1):105. [PubMed: 19368733]

21. Batty GD, Leon DA. Socio-economic position and coronary heart disease risk factors in children and young people. Eur J Public Health. 2002; 12:263-72. [PubMed: 12506501]

22. Okasha M, McCarron P, McEwan J, Davey Smith G. Childhood social class and adulthood obesity: findings from the Glasgow Alumni Cohort. J Epidemiol Community Health. 2003; 57:508-9. [PubMed: 12821695]

23. Li L, De Moira P, Power C. Changing influences on childhood obesity: a study of two generations of the 1958 British birth cohort. J Epidemiol Community Health. 2009; 63(Suppl 2):27.

24. Fairclough SJ, Boddy LM, Hackett AF, Stratton G. Associations between children's socioeconomic status, weight status, and sex, with screen-based sedentary behaviours and sport participation. Int J Pediatr Obes. 2009; 4:299-305. [PubMed: 19922045]

25. Jimenez-Pavon D, Kelly J, Reilly J. Associations between objectively measured habitual physical activity and adiposity in children and adolescents: Systematic review. Int J Pediatr Obes. 2009:116. Epub ahead of print.

26. Ness AR, Leary SD, Mattocks C, Blair SN, Reilly JJ, Wells J, Ingle S, Tilling K, Davey Smith G, Riddoch C. Objectively measured physical activity and fat mass in a large cohort of children. PLoS Med. 2007; 4:e97. [PubMed: 17388663]

27. Riddoch CJ, Mattocks C, Deere K, Saunders J, Tilling K, Leary SD, Blair SD, Ness AR. Objective measurement of levels and patterns of physical activity. Arch Dis Child. 2007; 92:963-9. [PubMed: 17855437]

28. McVey G, Tweed S, Blackmore E. Correlates of weight loss and muscle-gaining behaviour in 10to14-year old males and females. Prev Med. 2005; 40:1-9. [PubMed: 15530574] 


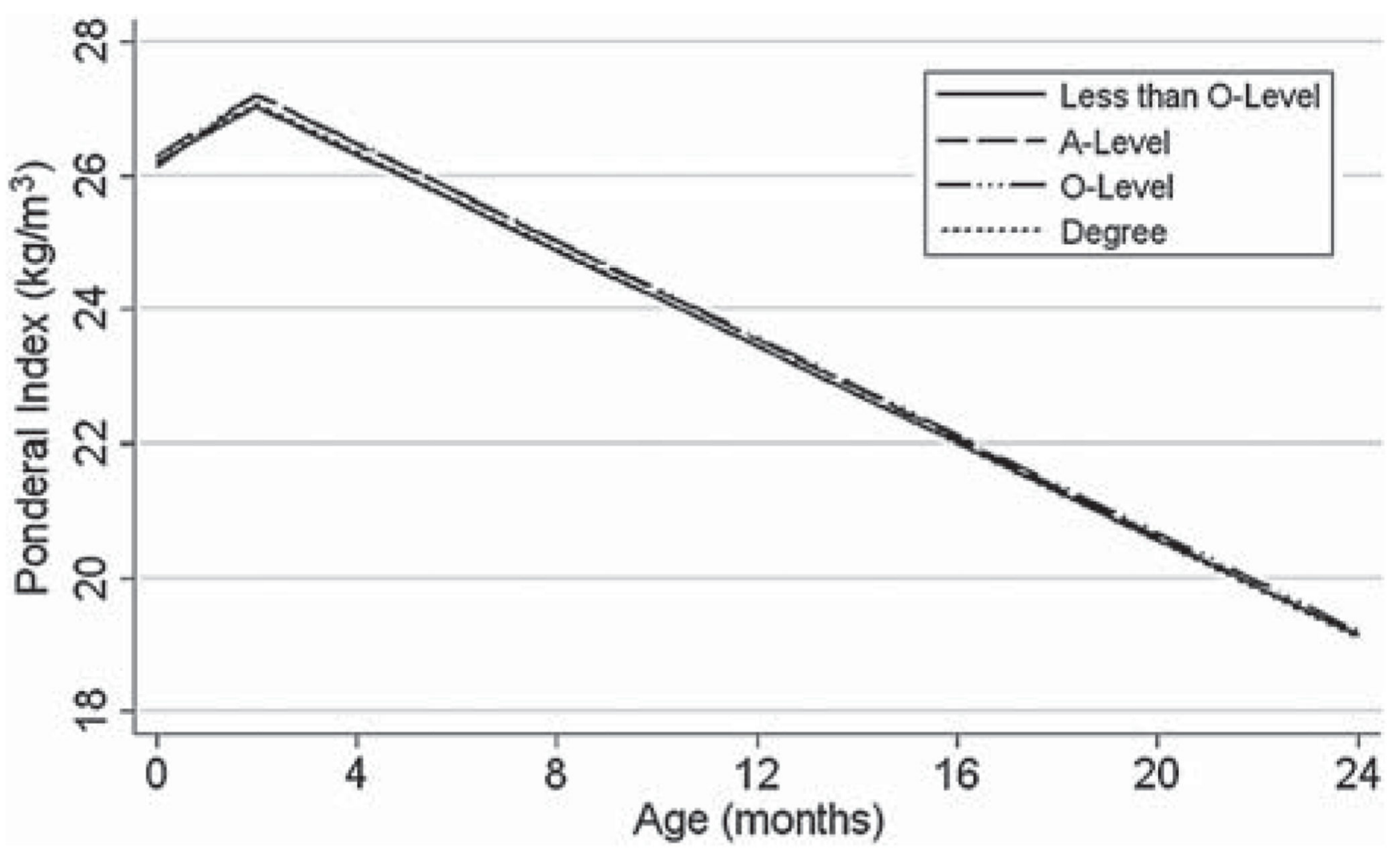

Figure 1.

Ponderal Index trajectories from birth to two years by category of maternal education (boys). 


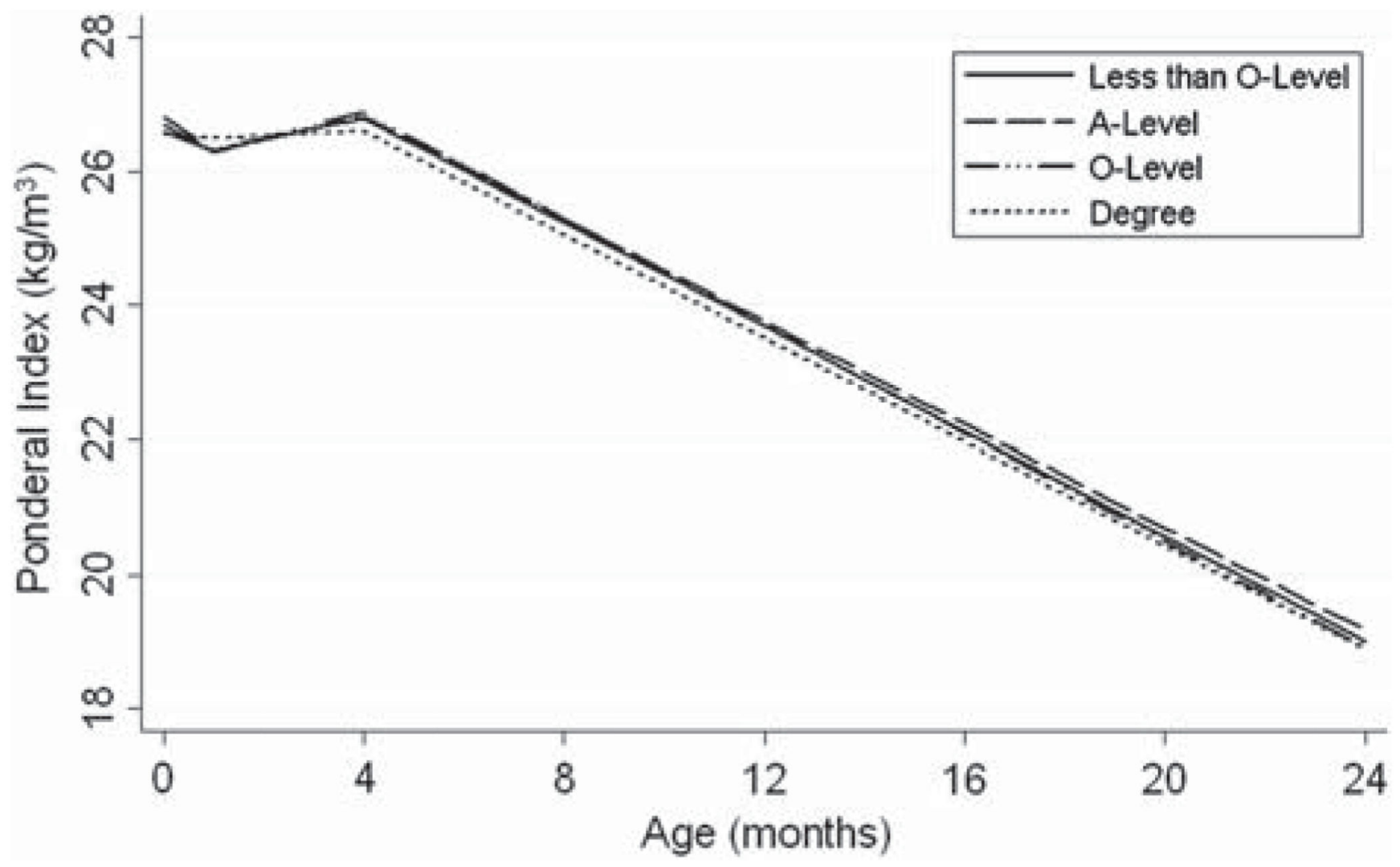

Figure 2.

Ponderal Index trajectories from birth to two years by category of maternal education (girls). 


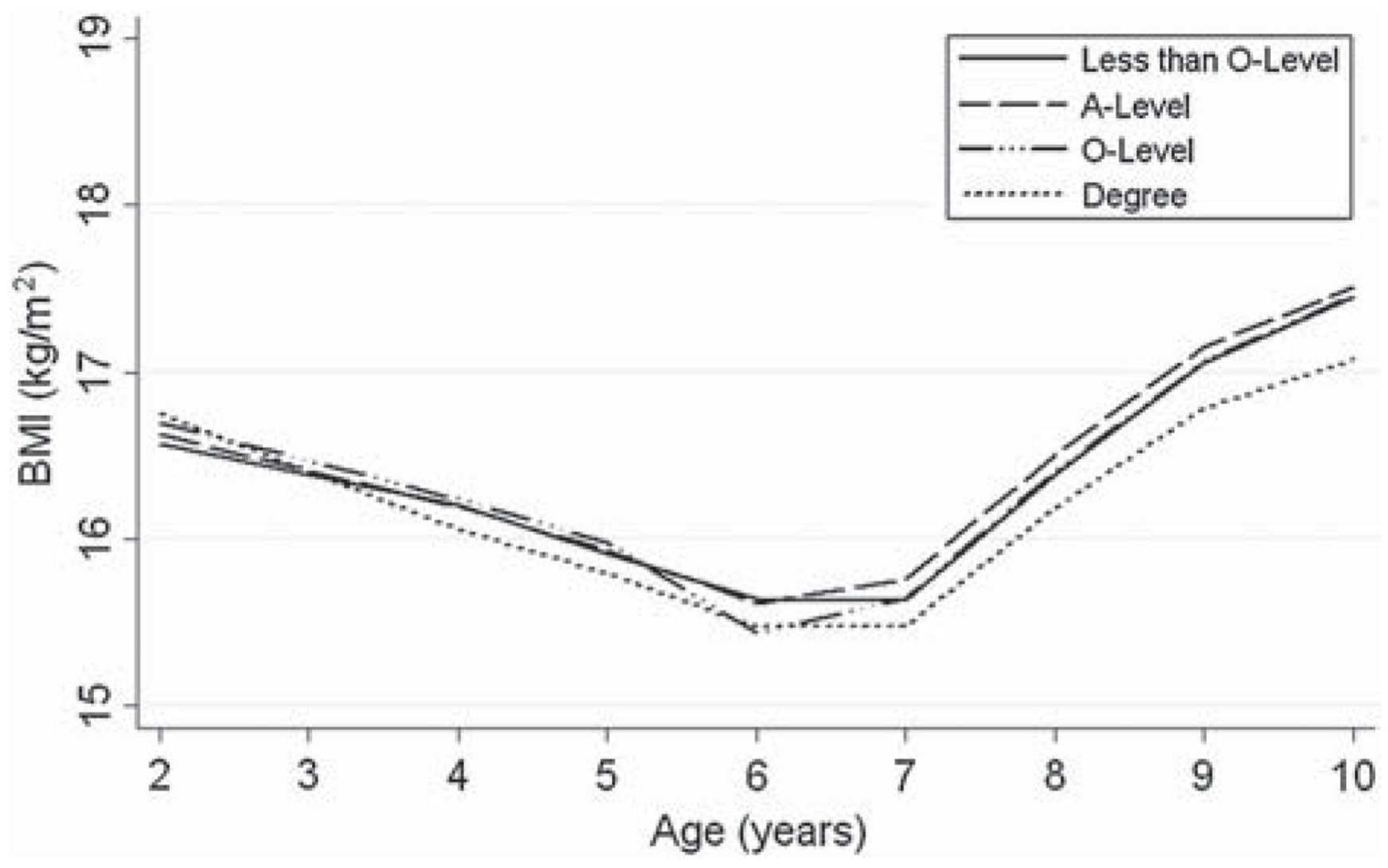

Figure 3.

Body Mass Index (BMI) trajectories from two to ten years by category of maternal education (boys). 


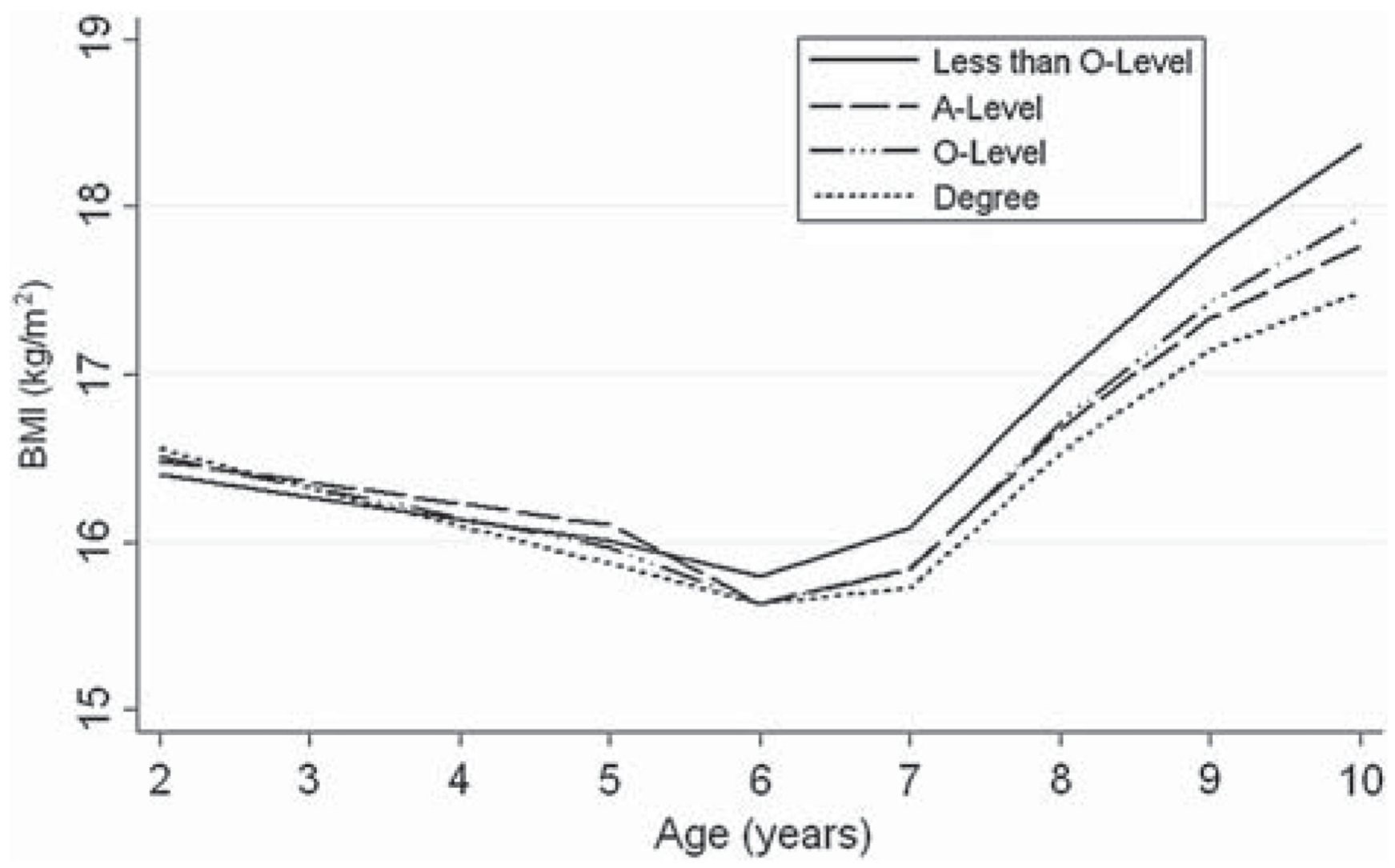

Figure 4.

Body Mass Index (BMI) trajectories from two to ten years by category of maternal education (girls). 


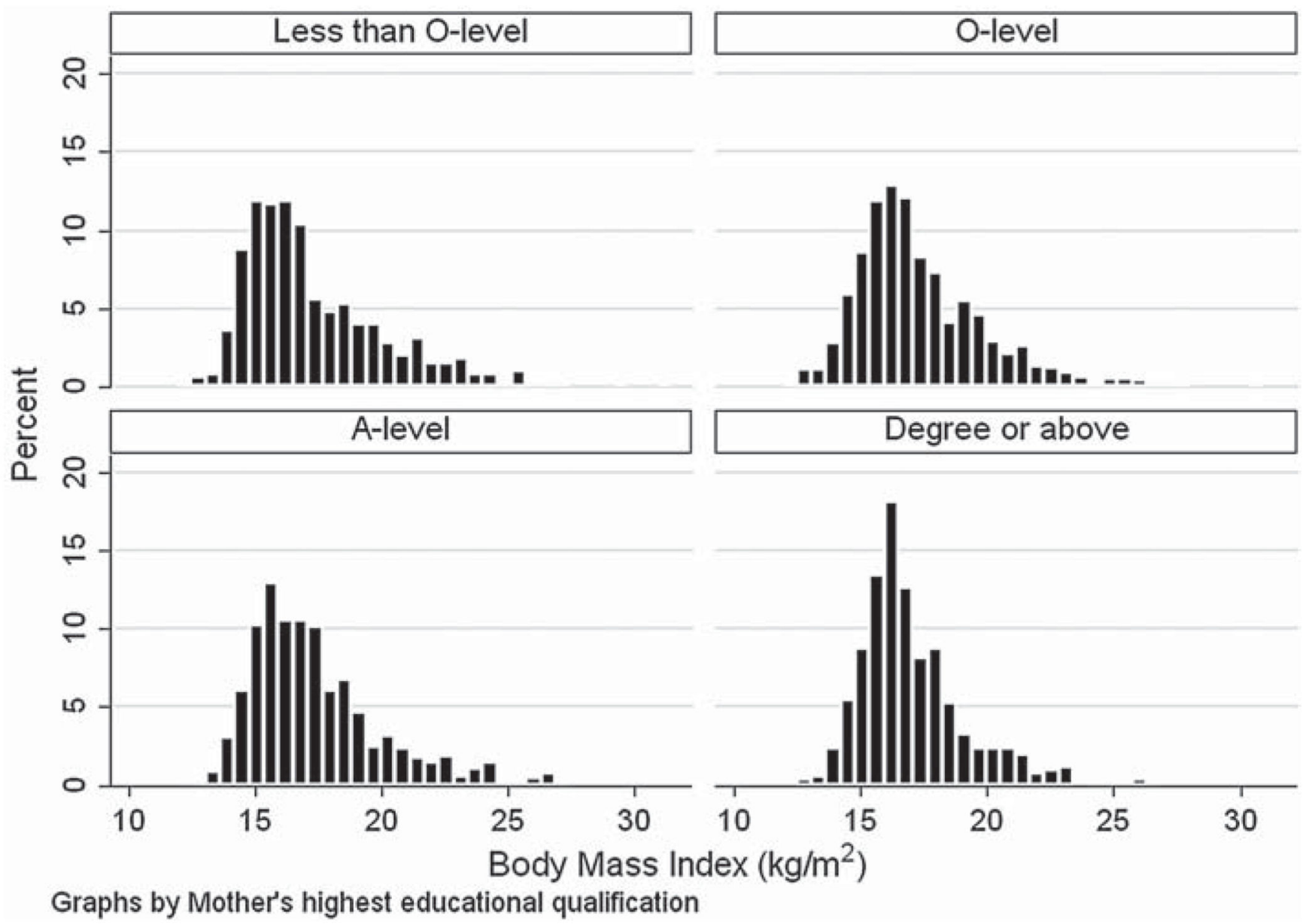

Figure 5.

Body Mass Index distribution by category of maternal education (boys). 


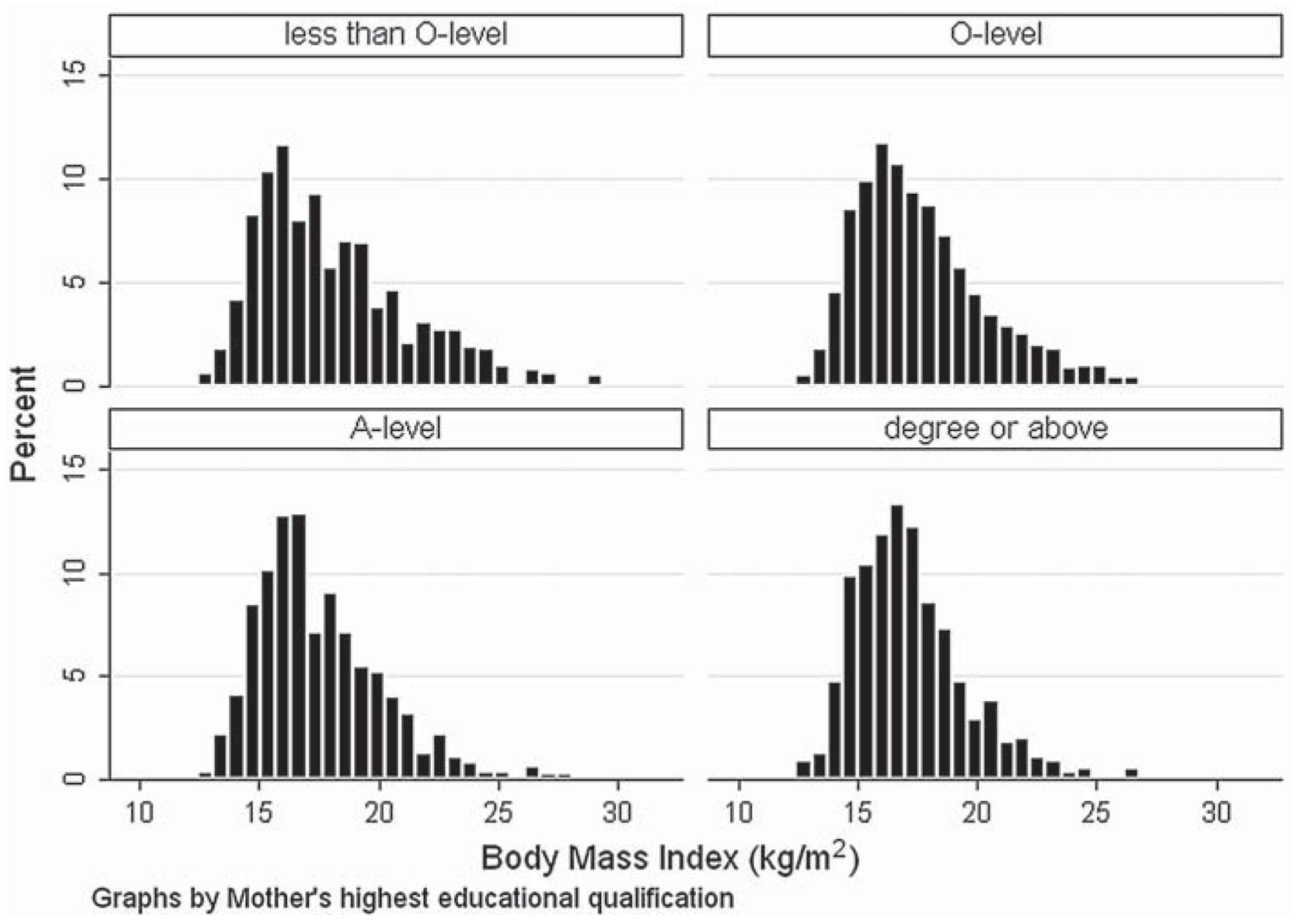

Figure 6.

Body Mass Index distribution by category of maternal education (girls). 


\section{Table I}

Characteristics of participants.

\begin{tabular}{llc}
\hline Characteristic & & N (\%) \\
\hline Sex & Boys in ponderal index model & 6323 \\
& Girls in ponderal index model & 5923 \\
& Boys in BMI model & 5850 \\
& Girls in BMI model & 5530 \\
Maternal education & Less than O-Level & $3685(30.1 \%)$ \\
& O-Level & $4253(34.7 \%)$ \\
& A-Level & $2742(22.4 \%)$ \\
Number of ponderal index measurements & Degree or above & $1566(12.8 \%)$ \\
& Median & 4 \\
Number of BMI measurements & IQR & 3 to 6 \\
& Median & 4
\end{tabular}

$\mathrm{BMI}=$ Body mass index; IQR: Inter-quartile range. 


\section{Table II}

Comparing actual measurements with measurements predicted by the models for ponderal index and body mass index.

\begin{tabular}{|c|c|c|c|c|}
\hline & \# Measures & $\begin{array}{l}\text { Mean actual measurement } \\
\text { (SD) }\end{array}$ & $\begin{array}{l}\text { Mean difference (actual - } \\
\text { predicted) }\end{array}$ & $95 \%$ level of agreement \\
\hline \multicolumn{5}{|l|}{ Boys } \\
\hline Ponderal index $\left(\mathrm{kg} / \mathrm{m}^{3}\right)$ : birth & 5305 & $26.03(2.60)$ & 0.076 & $-2.69,2.84$ \\
\hline 0 to $<2$ months & 5481 & $26.40(3.03)$ & -0.19 & $-3.91,3.53$ \\
\hline 2 to 24 months & 17503 & $23.58(3.31)$ & 0.040 & $-2.99,3.06$ \\
\hline BMI $\left(\mathrm{kg} / \mathrm{m}^{2}\right): 24$ months & 164 & $16.85(1.39)$ & 0.061 & $-0.65,0.76$ \\
\hline 24 to $<56$ months & 8927 & $16.40(1.44)$ & 0.0065 & $-1.00,0.96$ \\
\hline 56 to $<67$ months & 1281 & $16.02(1.74)$ & 0.054 & $-1.69,1.72$ \\
\hline 67 to $<73$ months & 2282 & $15.72(1.84)$ & -0.0099 & $-1.73,1.64$ \\
\hline 73 to $<79$ months & 619 & $15.78(2.11)$ & 0.19 & $-2.48,2.74$ \\
\hline 79 to $<105$ months & 6451 & $16.35(1.99)$ & 0.021 & $-0.89,0.84$ \\
\hline 105 to 120 months & 3563 & $17.29(2.54)$ & 0.0063 & $-0.98,0.90$ \\
\hline \multicolumn{5}{|l|}{ Girls } \\
\hline Ponderal index $\left(\mathrm{kg} / \mathrm{m}^{3}\right)$ : birth & 4974 & $26.36(2.64)$ & 0.013 & $-1.85,1.88$ \\
\hline 0 to $<1$ months & 586 & $25.43(3.00)$ & -0.30 & $-3.69,3.09$ \\
\hline 1 to $<4$ months & 7247 & $26.18(2.78)$ & 0.034 & $-2.30,2.37$ \\
\hline 4 to 24 months & 13720 & $23.02(3.18)$ & -0.015 & $-2.47,2.44$ \\
\hline BMI $\left(\mathrm{kg} / \mathrm{m}^{2}\right): 24$ months & 178 & $16.55(1.53)$ & 0.0060 & $-1.19,1.32$ \\
\hline 24 to $<60$ months & 8416 & $16.25(1.53)$ & -0.017 & $-1.28,0.92$ \\
\hline 60 to $<65$ months & 620 & $16.07(1.72)$ & 0.013 & $-1.27,1.59$ \\
\hline 65 to $<75$ months & 2628 & $15.66(1.93)$ & -0.059 & $-2.12,2.00$ \\
\hline 75 to $<81$ months & 603 & $15.92(2.25)$ & 0.18 & $-2.38,2.76$ \\
\hline 81 to $<103$ months & 4897 & $16.46(2.13)$ & -0.023 & $-0.73,0.68$ \\
\hline 103 to 120 months & 4921 & $17.53(2.68)$ & -0.025 & $-0.85,0.80$ \\
\hline
\end{tabular}

BMI=Body mass index; $\mathrm{SD}=$ Standard deviation. 


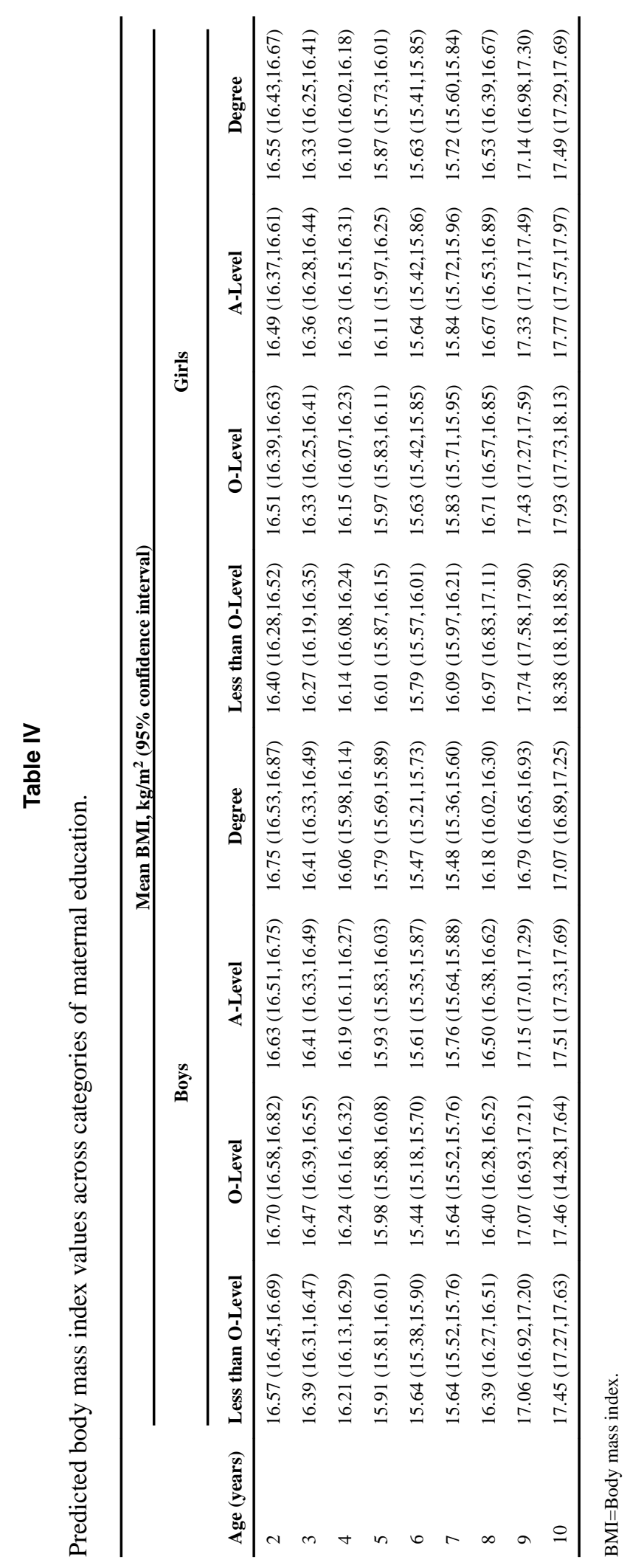

